\title{
PROPRIEDADES DA MADEIRA E ESTIMATIVAS DE MASSA, CARBONO E ENERGIA DE CLONES DE Eucalyptus PLANTADOS EM DIFERENTES LOCAIS ${ }^{1}$
}

\author{
Larissa Carvalho Santos², Ana Márcia Macedo Ladeira Carvalho³, Bárbara Luísa Corradi Pereira ${ }^{4}$, \\ Aylson Costa Oliveira ${ }^{5}$, Angélica de Cássia Oliveira Carneiro ${ }^{3}$ e Paulo Fernando Trugilho ${ }^{6}$
}

\begin{abstract}
RESUMO - As diferentes espécies de Eucalyptus são aptas para os mais diversos usos, sendo sua madeira amplamente empregada na geração de energia a partir da sua queima direta na forma de lenha ou da sua conversão em carvão vegetal. Além das propriedades da madeira, informações a respeito da estimativa de massa, carbono fixado e quantidade de energia disponível por área de plantio são importantes para a previsão da quantidade de produtos a ser gerada por material genético em dado local. Diante da importância que a matéria-prima, no caso a madeira, tem na produção de energia, este estudo objetivou, principalmente, estimar a massa, carbono e energia da madeira de três clones de Eucalyptus em diferentes locais, com o intuito de direcionar os clones que melhor se adaptam aos locais avaliados. Observou-se relação positiva entre incremento médio anual e acúmulo de massa de matéria seca de madeira, massa de carbono e energia. Não se verificou relação entre o local e a densidade, e não houve diferença significativa para poder calorífico superior entre os diferentes materiais. Os clones 1 e 3 apresentaram melhor desenvolvimento em Turmalina. Em Itacambira, os melhores resultados foram obtidos com o clone 2 .
\end{abstract}

Palavras-chave: Produtividade, Energia e Propriedades da madeira.

\section{PROPERTIES OF WOOD AND ESTIMATES OF MASS AND ENERGY OF Eucalyptus CLONES FROM DIFFERENT SITES}

\begin{abstract}
Different species of Eucalyptus are fit for many different uses, and their wood is widely applied for power generation from its direct burning, or by their conversion into charcoal. In addition to wood properties, information on the estimated mass, fixed carbon and energy available for the planting area is important for predicting the quantity of products to be generated by genetic material in a given site. Considering the importance that the raw material has in energy production, this study aimed at estimating the mass, energy and carbon in the wood of three clones of Eucalyptus, in order to direct the clones that are best suited to the sites evaluated. It was observed that there is a strong relationship between average annual increment and dry mass of wood, carbon mass and energy. It was not found a relationship between the location and density and significant differences between the calorific value for different materials in this study. Clones 1 and 3 have better development in Turmalina and in Itacambira, the best results were obtained for clone 2.
\end{abstract}

Keywords: Productivity, Energy and Wood properties.

\footnotetext{
${ }^{1}$ Recebido em 25.01.2012 aceito para publicação em 04.06.2012.

${ }^{2}$ Graduanda em Engenharia Florestal pela Universidade Federal de Viçosa. E-mail: <lari.carvalhoufv@ gmail.com>.

${ }^{3}$ Universidade Federal de Viçosa, Departamento de Engenharia Florestal.E-mail:<ana.marcia@ufv.br $>$ e $<$ cassiacarneiro1@gmail.com>.

${ }^{4}$ Programa de Pós-Graduação em Ciência Florestal pela Universidade Federal de Viçosa, Departamento de Engenharia Florestal. E-mail:<babicorradi@gmail.com>.

${ }^{5}$ Programa de Pós-Graduação em Ciência Florestal pela Universidade Federal de Viçosa, Departamento de Engenharia Florestal. E-mail: <aylsoncosta@gmail.com>.

${ }^{6}$ Universidade Federal de Lavras, Laboratório de Tecnologia da Madeira. E-mail: <trugilho@ufla.br>
} 


\section{INTRODUÇÃO}

O gênero Eucalyptus, predominantemente de ocorrência natural na Austrália, possui cerca de 700 espécies adaptadas às mais diversas condições de clima e solo (MONTAGU et al., 2003). O eucalipto foi introduzido no Brasil como cultura florestal em 1903 e, hoje, a eucaliptocultura no país é uma das mais avançadas do mundo, servindo de referência para outros países, inclusive para a Austrália. Segundo dados da ABRAF (2012), em 2011 a área ocupada por plantios florestais de Eucalyptus totalizava 4.873.952ha.

As diferentes espécies de eucaliptos são aptas para as mais diversas utilizações, sendo sua madeira amplamente empregada como matéria-prima no segmento de celulose e papel, além de serrarias, usinas de preservação, indústrias de painéis e chapas de madeira. Outro emprego importante é a geração de energia a partir da sua queima direta na forma de lenha, ou da sua conversão em subprodutos de maior valor energético como o carvão vegetal. Na geração de energia, a madeira do gênero Eucalyptus tem grande importância nos setores comercial, industrial e residencial. O carvão vegetal é excelente matéria-prima para a siderurgia brasileira, devido ao seu valor como combustível e termorredutor, elevado grau de pureza e baixo custo de produção, além de ser um produto renovável e ambientalmente correto quando oriundo de florestas plantadas (FREDERICO, 2009).

O conceito de florestas energéticas surgiu durante a década de 1980, para definir as plantações florestais com grande número de árvores por hectare e, consequentemente, de curta rotação, que tinham como finalidade a produção do maior volume de biomassa por área em menor espaço de tempo (MAGALHÃES, 2001). Nesse contexto, os estudos que visam à seleção de espécies em florestas energéticas de eucalipto propõem homogeneizar as propriedades da madeira e melhorar, além da eficiência de queima direta, rendimentos em carvão, teor de carbono e outras propriedades desejadas na sua utilização como termorredutor.

Segundo Trugilho et al. (2010), a produtividade do plantio é uma informação que deve se avaliada, através da estimativa de massa de madeira por área, para fazer a previsão da quantidade produzida por material genético em dado local, além da quantidade de carbono fixado. Essas informações servem para a tomada de decisão de aumento da área reflorestada e também da possibilidade de conseguir créditos de carbono com a floresta. Para Vale et al. (2000), a utilização de determinada madeira para fins energéticos deve basear-se, entre outros, no conhecimento do seu poder calorífico e no seu potencial para produção de biomassa.

O local de plantio e o ambiente onde a floresta é implantada também interferem na produção. Em Minas Gerais, os plantios estão distribuídos em diferentes regiões do Estado e apresentam diferentes taxas de incremento volumétrico, o qual sofre influência do material genético, do ambiente e da interação genótipo x ambiente (ZOBEL; JETT, 1995 citados por TRUGILHO, 2010).

Diante da importância da influência que a matériaprima tem sobre as características e propriedades do carvão vegetal, o conceito atual de produtividade florestal se encontra atrelado a um componente fundamental, a qualidade da madeira.

Assim, este estudo teve como objetivo principal determinar a densidade básica e poder calorífico, além de estimar massa, carbono e energia disponível na madeira de diferentes clones de Eucalyptus plantados em diferentes locais, com o intuito de direcionar os clones que melhor se desenvolvem em determinados ambientes.

\section{MATERIAL E MÉTODOS}

\subsection{Material Biológico}

Foram utilizados três clones híbridos de Eucalyptus urophylla (Tabela 1), provenientes de plantios comerciais de uma empresa florestal, nos Municípios de Turmalina e Itacambira, ambos localizados em Minas Gerais. Selecionaram-se árvores com diâmetro médio representativo de cada povoamento. Foram colhidas quatro árvores, por clone e local, totalizando 24 amostras. Os clones foram coletados em plantios comerciais com espaçamento de 3,0 × 3,0 m, aos 6 anos de idade, aproximadamente.

Itacambira faz parte da mesorregião Norte de Minas, cujo clima característico é tropical de altitude, e está localizada a $17^{\circ} 32543 \mathrm{~S}, 43^{\circ} 182323 \mathrm{~W}$. Turmalina, cujo clima é tropical, compõe a mesorregião Jequitinhonha, e se localiza a $17^{\circ} 17293 \mathrm{~S}, 42^{\circ} 432$ 483 W. Ambas as cidades se distanciam $97 \mathrm{~km}$. 
Tabela 1 - Clones híbridos de Eucalyptus urophylla utilizados no experimento, locais e respectivas características climáticas. Table 1 - Eucalyptus urophylla hybrid clones used in the experiment, and their local characteristics and climate.

\begin{tabular}{|c|c|c|c|c|}
\hline Local & $\begin{array}{l}\text { Material } \\
\text { genético }\end{array}$ & Altitude $(\mathrm{m})$ & $\begin{array}{l}\text { Pluviosidade } \\
\left(\mathrm{mm} / \mathrm{ano}^{-1}\right)\end{array}$ & $\begin{array}{l}\text { Temperatura } \\
\text { média }\left({ }^{\circ} \mathrm{C}\right)\end{array}$ \\
\hline & Clone 1 & & & \\
\hline Turmalina & $\begin{array}{l}\text { Clone } 2 \\
\text { Clone } 3 \\
\text { Clone } 1\end{array}$ & $450 / 1.020$ & 1028,5 & 23 \\
\hline Itacambira & $\begin{array}{l}\text { Clone } 2 \\
\text { Clone } 3\end{array}$ & $765 / 1480$ & 1082 & 22 \\
\hline
\end{tabular}

\subsection{Preparo das Amostras}

Foram retirados toretes de $0,1 \mathrm{~m}$ na base, a $25 \%$, $50 \%, 75 \%$ e $100 \%$ da altura comercial do tronco, considerado até um diâmetro mínimo de $7 \mathrm{~cm}$. De cada torete foi retirado um disco de faces paralelas, sendo deste obtidas duas cunhas opostas, utilizadas para determinação da densidade básica da madeira. O restante do disco foi utilizado para a produção de serragem, visando às análises da composição elementar e poder calorífico superior dos diferentes materiais genéticos estudados. As análises foram realizadas sob amostragem composta.

\subsection{Densidade Básica da Madeira}

Dos discos referentes às alturas amostradas, retiraram-se duas amostras opostas, em forma de cunha, passando pela medula, as quais foram identificadas e destinadas à determinação da densidade básica da madeira. Os procedimentos utilizados para a análise estão de acordo com o método de imersão em água, descrito por Vital (1984) e pela NBR 11941 (2003), utilizando-se uma balança hidrostática. Os valores foram calculados a partir da média aritmética das densidades das respectivas cunhas.

\subsection{Poder Calorífico Superior da Madeira}

O poder calorífico superior da madeira foi determinado de acordo com a metodologia descrita pela norma da ABNT NBR 8633 (2003), utilizando-se uma bomba calorimétrica adiabática.

\subsection{Teor de Carbono na Madeira}

Este teste foi feito conforme metodologia descrita por Ramos e Paula et al. (2011). O teor de carbono foi calculado aferindo-se uma massa equivalente a 2,0 mg
$( \pm 0,5)$ de serragem seca à temperatura de $(105 \pm 2)^{\circ} \mathrm{C}$, em um porta-amostra de estanho, previamente selecionada em peneiras sobrepostas de 200 e 270 mesh, sendo utilizada a fração retida nesta última. Em seguida, as amostras foram colocadas no carrossel do equipamento da marca Elementar®, modelo Vario Micro Cube CHNS-O. A análise foi realizada em uma amostra por vez. Os gases necessários para a operação foram o hélio, que é o gás de arraste, e o oxigênio, gás de ignição. A temperatura do tubo de combustão, localizado no interior do equipamento, no momento da queda da amostra do carrossel, foi de $1.150{ }^{\circ} \mathrm{C}$. Após a combustão, os gases foram transportados por arraste para o tubo de redução e dele seguiram para a coluna de detecção. O carbono, assim como os outros elementos, foi detectado através de um detector de termocondutividade, em que cada elemento tem interação e picoespecífico. O computador que estava acoplado ao equipamento realiza o cálculo da porcentagem de cada elemento, sendo considerado, neste estudo, somente o teor de carbono.

\subsection{Estimativas de Massa Seca de Madeira, Carbono e Energia}

A massa seca de madeira sem casca por hectare/ ano foi obtida multiplicando-se o incremento médio anual ( $\mathrm{m}^{3}$.ha.ano) da madeira sem casca pela densidade básica da madeira $\left(\mathrm{kg} \cdot \mathrm{m}^{-3}\right)$, conforme a equação (1):

$$
\mathrm{MSM}=\mathrm{IMA} \times \mathrm{X} \text { Dbm }
$$

em que:

MSM = massa seca de madeira $\left(\mathrm{t} \cdot \mathrm{ha}^{-1} \cdot \mathrm{ano}^{-1}\right) ;$
$\mathrm{IMA}=$ incremento médio anual $\left(\mathrm{m}^{3} \cdot \mathrm{ha}^{-1} \cdot \mathrm{ano}^{-1}\right) ; \mathrm{e}$
Dbm $=$ densidade básica da madeira $\left(\mathrm{kg} \cdot \mathrm{m}^{-3}\right)$.

Revista Árvore, Viçosa-MG, v.36, n.5, p.971-980, 2012 
A massa de carbono (expressa em tonelada) foi obtida multiplicando-se a massa seca de madeira pela porcentagem de carbono na madeira, conforme a equação(2).

$$
\mathrm{MC}=\mathrm{MSM} \times \mathrm{C}
$$

em que:

$\mathrm{MC}=$ massa de carbono $\left(\mathrm{t} \cdot \mathrm{ha}^{-1} \cdot \mathrm{ano}^{-1}\right) ;$

$\mathrm{Msm}=\mathrm{MSM}=$ massa seca da madeira $\left(\mathrm{t} \cdot \mathrm{ha}^{-1} \cdot \mathrm{ano}^{-1}\right) ; \mathrm{e}$ $\mathrm{C}(\%)=$ porcentagem de carbono/100.

Para o cálculo da quantidade de energia por hectare/ ano, expressa em kW.h, multiplicou-se a massa de matéria seca da madeira pelo poder calorífico superior, fazendo-se a equivalência de $1 \mathrm{kWh}$ a $859,85 \mathrm{kcal}$, calculado pela equação (3).

Energia Disponível = MSM x PCS mad em que:

Energia Disponível $=$ energia por hectare. ano $(\mathrm{kW} . \mathrm{h}$. ha $^{-1} \cdot$ ano $\left.^{-1}\right)$;

Msm $=$ massa seca da madeira $\left(\mathrm{t} \cdot \mathrm{ha}^{-1} \cdot \mathrm{ano}^{-1}\right) ; \mathrm{e}$

PCS $\operatorname{mad}=$ poder calorífico superior da madeira $\left(\mathrm{kcal}_{\mathrm{kg}} \mathrm{kg}^{-1}\right.$.

\subsection{Análise Estatística dos Dados}

Para avaliar o efeito das diferentes regiões e dos clones nas propriedades da madeira e nas estimativas de massa e energia, instalou-se um fatorial completo no delineamento inteiramente casualizado, em que foram comparados duas regiões de plantio e três clones, com quatro repetições (árvores), totalizando seis tratamentos e 24 observações.

Os dados foram submetidos aos testes de Lilliefors para testar a normalidade e de Cochran para testar a homogeneidade das variâncias e, em seguida, submetidos à análise de variância (ANOVA). Estabelecidas as diferenças significativas, foram feitos os devidos desdobramentos, sendo os tratamentos comparados entre si, por meio do teste de Tukey a $5 \%$ de probabilidade e $95 \%$ de significância.

\section{RESULTADOS}

\subsection{Incremento Médio Anual (IMA)}

Na Tabela 2 são apresentados os incrementos médios anuais (IMAs), observados em cada clone, nos diferentes locais.

Revista Árvore, Viçosa-MG, v.36, n.5, p.971-980, 2012
Tabela 2 - Incrementos Médios Anuais (IMAs), em m³/ha.ano, observados nos três clones desenvolvidos em Turmalina e Itacambira, MG, considerando-se a madeira sem casca.

Table 2 - Average annual increment (IMAs) in $\mathrm{m}^{3} / \mathrm{ha} /$ year, found for the three clones, developed in Itacambira and Turmalina, Minas Gerais State.

\begin{tabular}{ccc}
\hline Clone & Turmalina & Itacambira \\
\hline 1 & 43,40 & 31,95 \\
2 & 39,18 & 39,07 \\
3 & 44,51 & 31,68 \\
\hline
\end{tabular}

Turmalina apresentou condições mais favoráveis ao desenvolvimento dos clones, uma vez que o incremento médio anual de todos os clones foi superior nesse local. Em ordem decrescente, os maiores IMAs observados nesse local foram: clone 3 , clone 1 e clone 2 . Em Itacambira: clone 2, clone 1 e clone 3.

Na Tabela 3, encontra-se o resumo da análise de variância (ANOVA) das propriedades da madeira (densidade básica e poder calorífico superior) e das estimativas de massa de madeira seca, massa de carbono e quantidade de energia por hectare/ano.

Observou-se que, na densidade básica, apenas o fator clone foi significativo a $5 \%$ de probabilidade e que não havia interação entre os fatores clone e local de plantio; para o poder calorífico superior, nenhum dos fatores analisados (clone e local) foi significativo, ou seja, não houve diferença significativa de poder calorífico superior (PCS) nos diferentes materiais avaliados, a $5 \%$ de probabilidade; já para a porcentagem de carbono e estimativas de massa de matéria seca de madeira, massa de carbono e energia disponível, foi significativo o efeito dos fatores clone e local, e verificou-se também a interação significativa entre eles pelo teste $\mathrm{F}(\mathrm{p}<0,05)$, necessitando-se do desdobramento das interações.

\subsection{Densidade Básica da Madeira}

Os valores médios da densidade básica da madeira dos diferentes materiais genéticos de eucalipto são mostrados na Figura 1.

A densidade básica da madeira dos diferentes clones não foi afetada pelas regiões analisadas. Houve somente diferenças significativas de densidade básica da madeira entre clones, a 5\% de probabilidade. Verifica-se, pelo gráfico da Figura 1, que a densidade dos clones 1 e 3 diferiram entre si, mas que o clone 2 não diferiu 
Tabela 3 - Resumo da análise de variância dos dados referentes à densidade básica e poder calorífico superior da madeira, estimativas de massa de madeira seca, massa de carbono e quantidade de energia por hectare/ano.

Table 3 - Summary of analysis of variance of data concerning the density and calorific value of wood, estimates of dry wood mass, carbon mass and amount of energy per hectare per year.

\begin{tabular}{cccccccc}
\hline Fonte de variação & \multirow{2}{*}{ GL } & \multicolumn{5}{c}{ Quadrado médio } \\
\cline { 2 - 7 } & & Densidade & PCS & C $(\%)$ & MSM & MC & Energia \\
\hline Clone & 2 & $0,004863^{*}$ & $5657,70^{\mathrm{NS}}$ & $0,40^{\mathrm{NS}}$ & $6,202^{*}$ & $1,268^{*}$ & $165826830,00^{*}$ \\
Local & 1 & $0,000000^{\mathrm{NS}}$ & $4830,84^{\mathrm{NS}}$ & $0,95^{\mathrm{NS}}$ & $99,453^{*}$ & $20,229^{*}$ & $2870461556,95^{*}$ \\
Clone*Local & 2 & $0,000611^{\mathrm{NS}}$ & $14910,59^{\mathrm{NS}}$ & $9,66^{*}$ & $34,209^{*}$ & $5,201^{*}$ & $893682756,28^{*}$ \\
Erro & 18 & 0,000607 & 4984,98 & 2,57 & 0,941 & 0,349 & 28561020,22 \\
Total & 23 & & & & & & \\
\hline
\end{tabular}

$\mathrm{GL}=$ graus de liberdade; $\mathrm{PCS}=$ poder calorífico superior da madeira; $\mathrm{C}(\%)=$ porcentagem de carbono na madeira; $\mathrm{MSM}=\mathrm{Massa}$ de matéria seca de madeira; $\mathrm{MC}=$ Massa de carbono; $*$ = significativo a $5 \%$ de probabilidade, pelo teste $\mathrm{F} ; \mathrm{e}^{\mathrm{NS}}=$ não significativo a $5 \%$ de probabilidade, pelo teste $\mathrm{F}$. $\mathrm{DF}=$ degrees of freedom; HCFW = higher calorific force of the wood; $\mathrm{C}(\%)=$ percentage of carbon in the wood; DMM $=$ Wood dry matter mass; $\mathrm{CM}=$ carbon mass; * significant at $5 \%$ of probability by the $\mathrm{F}$ test; NS = non-significant at $5 \%$ of probability by the $\mathrm{F}$ test.

Médias seguidas de mesma letra não diferem entre si, pelo teste de Tukey a $5 \%$ de probabilidade.

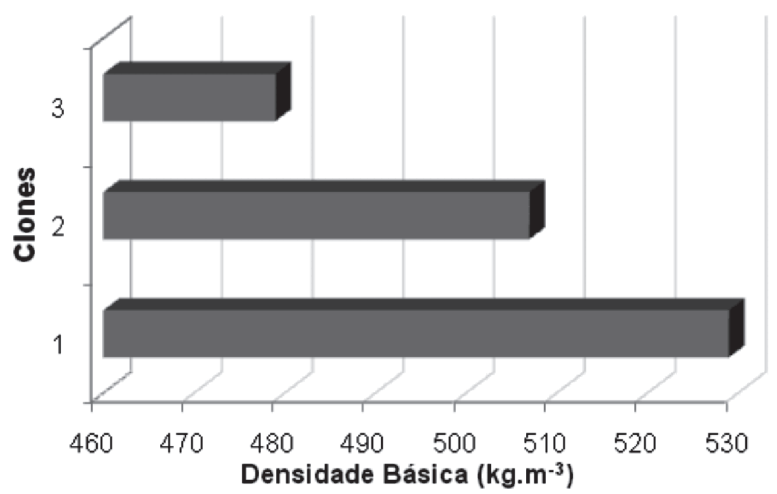

Figura 1 - Densidade básica média da madeira, em $\mathrm{kg} \cdot \mathrm{m}^{-3}$, dos diferentes clones de Eucalyptus.

Figure 1 -Average basic wood density in $\mathrm{g} / \mathrm{cm}^{3}$, the different clones of Eucalyptus.

significativamente dos demais. A maior densidade básica da madeira foi observada no clone $1\left(529 \mathrm{~kg} . \mathrm{m}^{-3}\right)$, seguido pelo clone $2\left(507 \mathrm{~kg} \cdot \mathrm{m}^{-3}\right)$, e a menor densidade foi apresentada pelo clone $3\left(479 \mathrm{~kg} \cdot \mathrm{m}^{-3}\right)$.

\subsection{Poder Calorífico Superior}

Não houve diferenças significativas a $5 \%$ de probabilidade para o PCS, sendo este, em média, $4.456 \mathrm{kcal} . \mathrm{kg}^{-1}$.

\subsection{Teor de Carbono}

Na Tabela 4 são apresentados os valores médios do teor de carbono e das estimativas da massa seca, massa de carbono e energia, em função dos clones e locais.
Tabela 4 - Valores médios do teor de carbono da madeira, em $\%$, e das estimativas de massa de matéria seca de madeira, massa de carbono e energia dos diferentes clones estudados, desenvolvidos em Turmalina e Itacambira, MG.

Table 4-Mean values of carbon content in the wood, in $\%$, and estimates of dry mass of the wood, carbon mass and energy for the different clones, developed in Tourmaline and Itacambira, Minas Gerais State.

\begin{tabular}{ccc}
\hline Clones & Turmalina & Itacambira \\
\hline \multicolumn{4}{c}{ Carbono (\%) } \\
1 & $45,81 \mathrm{bA}$ & $48,59 \mathrm{aA}$ \\
2 & $47,53 \mathrm{aA}$ & $45,99 \mathrm{aA}$ \\
3 & $47,06 \mathrm{aA}$ & $47,01 \mathrm{aA}$ \\
& Massa seca de madeira $\left(\mathrm{t} / \mathrm{ha}^{-1} \cdot \mathrm{ano}^{-1}\right)$ \\
1 & $23,28 \mathrm{aA}$ & $16,5 \mathrm{bB}$ \\
2 & $19,49 \mathrm{aC}$ & $20,18 \mathrm{aA}$ \\
3 & $21,40 \mathrm{aB}$ & $15,27 \mathrm{bB}$ \\
& $10,66 \mathrm{aA}$ & $8,02 \mathrm{bB}$ \\
1 & $9,27 \mathrm{aB}$ & $9,29 \mathrm{aA}$ \\
2 & $10,07 \mathrm{aAB}$ & $7,18 \mathrm{bB}$ \\
3 & Carbono $\left(\mathrm{t} . \mathrm{ha}^{-1} \mathrm{ano}^{-1}\right)$ & $84971,36 \mathrm{bB}$ \\
& Energia Disponível (kW.h. ha- $\left.{ }^{-1} \cdot \mathrm{ano}^{-1}\right)$ \\
2 & $122428,60 \mathrm{aA}$ & $103169,31 \mathrm{aA}$ \\
3 & $100980,57 \mathrm{aB}$ & $79953,66 \mathrm{bB}$ \\
\hline
\end{tabular}

Médias seguidas pela mesma letra minúscula na linha ou pela mesma letra maiúscula na coluna não diferem entre si, pelo teste de Tukey a $5 \%$ de probabilidade.

Os valores médios do teor de carbono da madeira dos diferentes clones e locais são mostrados na Tabela 4. Não foram observadas diferenças significativas entre clones ou locais, porém houve interação significativa entre clone e local de plantio, a $5 \%$ de probabilidade, ou seja, o comportamento do fator clone depende do local, havendo dependência entre os fatores.

Revista Árvore, Viçosa-MG, v.36, n.5, p.971-980, 2012 
Os valores médios da porcentagem de carbono foram próximos entre si. Apenas no clone 1 houve diferenças significativas a $5 \%$ de probabilidade, nos locais de plantio: o teor de carbono da madeira do clone 1 em Itacambira era estatisticamente superior ao de Turmalina.

\subsection{Massa de matéria seca de madeira (MSM), Massa de Carbono e Energia Disponível}

\subsubsection{Massa seca de madeira}

Comparando os clones em Turmalina, todos diferiram significativamente entre si, acompanhando o incremento médio anual desses clones naquele local, sendo a massa de matéria seca de madeira do clone 1 estatisticamente superior à dos clones 2 e 3 . Em Itacambira, os clones 1 e 3 diferiram significativamente do clone 2 , tendo este apresentado maior valor estimado de massa de matéria seca, acompanhando o maior IMA desse clone em relação aos demais.

Localmente, os clones 1 e 3 diferiram significativamente entre Turmalina e Itacambira, ambos apresentando maior massa de matéria seca em Turmalina. Entre todos os clones, o clone 1, em Turmalina, foi o que apresentou maior massa de matéria seca de madeira, valendo ressaltar que, além de seu alto IMA, a densidade básica da sua madeira foi superior à dos clones 2 e 3 .

\subsubsection{Massa de carbono}

Analisando os diferentes clones, em Turmalina o maior valor médio encontrado foi no clone 1 , tendo este não se diferenciado estatisticamente do clone 3 , que por sua vez também não se diferenciou do clone 2, que obteve menor massa de carbono/ha.ano. Em Itacambira, porém, maior valor foi obtido no clone 2 , a exemplo da MSM, diferindo-se estatisticamente dos clones 1 e 3 , que apresentaram o menores valores.

Comparando os diferentes locais, apenas o clone 2 não apresentou diferenças em acúmulo de massa de carbono em função dos locais. Os clones 1 e 3 tiveram maior massa de carbono acumulada em Turmalina.

\subsubsection{Energia disponível}

Quanto à estimativa de energia estocada por hectare/ ano, verificou-se que o clone 1, em Turmalina, apresentou maior quantidade de energia, o que pode ser explicado por sua elevada massa de matéria seca. Os demais clones

Revista Árvore, Viçosa-MG, v.36, n.5, p.971-980, 2012 não apresentaram, naquela localidade, diferenças significativas. Lá, também acompanhando os resultados de massa seca, o clone 2 destacou-se estatisticamente dos demais, apresentando maior quantidade de energia disponível por hectare.ano.

Comparando os diferentes locais, os clones $1 \mathrm{e}$ 3 apresentaram diferenças significativas, ambos com maior quantidade de energia por hectare em Turmalina, corroborando os resultados de massa de carbono e massa seca.

\section{DISCUSSÃO}

\subsection{Incremento Médio Anual}

Segundo a ABRAF (2012), a produtividade média ponderada, em função da área plantada, dos plantios de Eucalyptus de suas empresas associadas, que em 2005 era de $36,7 \mathrm{~m}^{3} \cdot \mathrm{ha}^{-1}$. ano $^{-1}$, em 2011 atingiu $40,1 \mathrm{~m}^{3} \cdot \mathrm{ha}^{-1}$. ano ${ }^{-1}$. Os clones 1 e 3 que cresceram em Turmalina apresentaram IMAs superiores à média da produtividade das empresas associadas à ABRAF. Neste estudo, tal localidade apresentou melhores condições ao desenvolvimento dos clones. Uma hipótese para justificar o maior valor de IMA apresentado é o índice pluviométrico superior desse local, que favoreceu o desenvolvimento dos indivíduos estudados. Outro fator que também pode ter contribuído para tal diferença são as condições edáficas.

De acordo com Gomide et al. (2005), nas últimas décadas, no Brasil, houve ampla evolução no aspecto de produtividade das florestas de Eucalyptus, alcançando-se os mais elevados níveis mundiais de incremento médio anual (IMA), devido a diversas pesquisas em melhoramento genético e otimização do manejo florestal. Vale ressaltar que as pesquisas não objetivam apenas aumentar a produtividade, mas também buscam adequar as características da madeira para cada uso a que se destina, garantindo a melhoria da qualidade do produto final.

\subsection{Densidade Básica da Madeira}

Quanto à densidade básica, como apenas o fator clone foi significativo, pode-se inferir que a densidade da madeira é uma propriedade muito mais influenciada pela herança genética que pelo ambiente, como foi dito por Trugilho et al. (2010), ao afirmarem que tanto o volume individual da árvore quanto a densidade básica e a estimativa de massa de matéria seca estão sob forte 
controle genético. Frederico (2009) também verificou que a densidade da madeira de três clones de Eucalyptus aos 7 anos de idade não foi afetada em diferentes regiões em que esses clones se desenvolveram, apesar das diferenças entre a fertilidade do solo e a pluviosidade. Contudo, os fatores ambientais também têm influência no crescimento e propriedades da madeira.

Trugilho et al. (2001), analisando clones de Eucalyptus aos 7 anos, referiram-se à densidade básica da madeira como a propriedade que mais influencia a qualidade do carvão vegetal. Esses autores concluíram que os clones que apresentaram densidade variando de 520 a $590 \mathrm{~kg} \cdot \mathrm{m}^{-3}$ foram potenciais para a produção de carvão. Os valores observados neste trabalho variaram entre 479 e $529 \mathrm{~kg} . \mathrm{m}^{-3}$ semelhantes aos encontrados na literatura para clones do gênero Eucalyptus para esse mesmo fim (ROCHA, 2010; SANTOS et al., 2011).

Para a produção de carvão vegetal, também é favorável o uso de madeiras de alta densidade básica, fator que afeta sobremaneira os custos da operação. Isso porque madeira de alta densidade gera carvão de alta densidade, o que reduz o custo de transporte, além de fornecer maior rendimento, jáque para um mesmo volume do forno madeiras mais densas representam maior massa enfornada, quando comparadas com madeiras menos densas. Além disso, no emprego direto para a geração de energia a partir da queima na forma de lenha, a madeira de maior densidade resulta num combustível de maior energia concentrada, devido à maior massa de combustível contida na mesma unidade de volume (FREDERICO, 2009).

O efeito significativo encontrado em clone, local e na interação deles para a porcentagem de carbono e estimativas de massa de matéria seca de madeira, massa de carbono e energia disponível sugerem que esses aspectos são dependentes e, ainda, sofrem influência da carga genética, o que explica a variação entre os clones, mas também do ambiente, que pode oferecer condições mais ou menos favoráveis para o desenvolvimento do indivíduo. Esse aspecto é responsável pela diferença entre os locais, quando se analisa o mesmo clone, e também pela interação entre os fatores.

\subsection{Poder Calorífico Superior}

Em se tratando de poder calorífico superior, não houve diferenças significativas a 5\% de probabilidade. Uma hipótese para explicar esses valores não discrepantes é que o poder calorífico superior é característica genética da espécie, não variando entre clones ou entre os locais onde foram plantados. Tal fato pode ser verificado em diversos trabalhos que avaliam o poder calorífico de espécies do gênero Eucalyptus.

Quirino et al. (2004), avaliando o poder calorífico superior de algumas espécies florestais, entre elas alguns eucaliptos, obtiveram como valor médio para Eucalyptus urophyla $4.499 \mathrm{kcal} / \mathrm{kg}$. Resultados semelhantes foram obtidos por Santos et al. (2011), que estudaram quatro clones híbridos de Eucalyptus sp., aos 7 anos, e obtiveram valores que variaram de 4.274 a $4.585 \mathrm{kcal} \mathrm{kg}^{-1}$. Castro (2011) avaliou três clones de Eucalyptus spp. com idades de 3, 4, 5 e 7 anos, obtendo valores que variaram de 4.480 a $4.4719 \mathrm{kcal} \mathrm{kg}^{-1}$. Vale et al. (2000), estudando diferentes doses de fertilizantes em $E$. grandis, concluíram que não houve influência da adubação no poder calorífico superior dos indivíduos avaliados.

Podem-se extrapolar esses resultados para o caso estudado neste trabalho, concluindo que o local não exerce influência sobre o PCS, que apresenta pequena variação dentro do gênero Eucalyptus.

\subsection{Teor de Carbono}

Para teor de carbono da madeira somente houve interação significativa entre clone e local de plantio, a $5 \%$ de probabilidade. O comportamento do fator clone depende do local onde se encontra, havendo dependência entre os fatores. Apenas o clone 1 apresentou diferença quanto ao teor de carbono nos dois locais de plantio, tendo os indivíduos de Itacambira teor de carbono estatisticamente superior aos de Turmalina.

De modo geral, o percentual de carbono não há grandes diferenças em relação ao teor de carbono na madeira de diferentes espécies do gênero Eucalyptus (ARANTES, 2009; SANTOS et al., 2011), variando de 45 a $50 \%$. Deve ser ressaltado que os teores de carbono, assim como de outros elementos na madeira, podem ser influenciados pelo tipo de solo e pela adubação. Os valores encontrados neste trabalho variam entre $45,81 \%$ e $48,59 \%$.

Quando se objetiva a produção de carvão vegetal ou a queima direta da madeira, maiores teores de carbono são desejáveis. Na produção de carvão vegetal, o carbono é convertido em carbono fixo, e é o principal responsável

Revista Árvore, Viçosa-MG, v.36, n.5, p.971-980, 2012 
pela energia estocada. Já na queima direta o carbono é totalmente consumido, e espera-se que madeiras que têm maiores teores de carbono possuam também maior capacidade térmica em função da maior energia liberada (SANTOS et al., 2011).

\subsection{Massa Seca de Madeira}

Em termos de massa de matéria seca de madeira (MSM), em Turmalina todos os clones diferiram significativamente entre si, o que pode ser explicado pelo IMA dos clones desse local. A MSM do clone 1 foi estatisticamente superior à dos demais. Em Itacambira, o clone 2 apresentou maior valor estimado de massa de matéria seca, acompanhando o maior IMA desse clone, em comparação com os clones 1 e 3 .

Quanto ao local, os clones 1 e 3 tiveram comportamentos diferentes em Turmalina e Itacambira, ambos apresentando maior massa de matéria seca em Turmalina. Esses mesmos clones mostraram maior IMA em Turmalina, evidenciando dependência entre a produtividade, dada pelo IMA, e a massa de matéria seca de madeira.

Os valores deste estudo são superiores aos encontrados por Rocha (2011), que, analisando um clone de eucalipto (híbrido de Eucalyptus grandis $x$ Eucalyptus camaldulensis) em diferentes idades e espaçamentos, obteve no espaçamento de 3,0 x 3,0 $\mathrm{m}$ e idade de 77 meses (aproximadamente 6,5 anos), uma produção de massa de matéria seca de madeira de 17,31 t/ha.ano.

Quando o objetivo é a utilização de madeira para fins energéticos, fica evidente a importância da produtividade volumétrica e da densidade básica, uma vez que esses dois parâmetros determinam a produção de massa seca de madeira (ROCHA, 2011). Assim, para a produção de energia, através da queima direta ou produção de carvão vegetal, a quantificação de massa de madeira é mais importante do que a utilização dos parâmetros dendrométricos, como o diâmetro, a altura e o volume de madeira (OLIVEIRA et al., 1991).

\subsection{Massa de Carbono}

Esses valores foram determinados considerando os valores médios de porcentagem de carbono na madeira e os valores médios das estimativas de massa de matéria seca. Como não houve diferença expressiva do teor de carbono dos clones avaliados, a massa de matéria seca de madeira teve maior influência na massa de

Revista Árvore, Viçosa-MG, v.36, n.5, p.971-980, 2012

Revista Árvore, Viçosa-MG, v.36, n.5, p.971-980, 2012 carbono. Portanto, os clones que apresentaram maiores valores de massa seca de madeira também exibiram maiores massas de carbono, assim como aqueles que tiveram menores valores de massa de matéria seca apresentaram também menores massas de carbono.

Analisando os diferentes clones, em Turmalina o maior valor médio encontrado para massa de carbono foi no clone 1 , tendo este não se diferenciado estatisticamente do clone 3 , que por sua vez não se diferenciou do clone 2. Em Itacambira, porém, maior massa de carbono foi obtida no clone 2, diferindo estatisticamente dos clones 1 e 3 .

Comparando os diferentes locais, apenas o clone 2 não apresentou diferenças em acúmulo de massa de carbono em função dos locais. O clone 1 teve maior massa de carbono acumulada em Turmalina, assim como o clone 3 .

Os valores aqui encontrados são próximos aos de Rocha (2011), que obteve massa de carbono correspondente a 8,66 t/ha.ano na idade de 77 meses.

\subsection{Energia Disponível}

O clone 1 foi o que apresentou maior quantidade de energia estocada por hectare.ano em Turmalina. Vale et al. (2000) atribuíram a superioridade energética à maior produção de massa de matéria seca, justificativa que pode ser aplicada ao clone 1. Em Itacambira, corroborando os resultados de massa de matéria seca, o clone 2 destacou-se estatisticamente dos demais, apresentando maior quantidade de energia disponível por hectare.ano.

Em termos locais, os clones 1 e 3 apresentaram diferenças significativas, ambos com maior quantidade de energia/ha em Turmalina, em concordância com os resultados de massa de carbono e massa de matéria seca.

Para a estimativa de energia, deve-se considerar, ainda, que o poder calorífico superior da madeira não apresentou diferenças significativas nos clones e locais analisados, ou seja, esse parâmetro não influenciou na quantidade de energia disponível, ficando esta somente dependente da massa de matéria seca de madeira, em relação diretamente proporcional.

\section{CONCLUSÕES}

A densidade básica da madeira dos diferentes clones não foi afetada pelas regiões analisadas, apresentando 
variações apenas no nível de clone, o que permite inferir ser essa uma característica determinada pela carga genética do material estudado;

Em relação ao teor de carbono, apenas o clone 1 apresentou diferenças significativas quanto ao local, com maiores valores observados em Itacambira.

Quando houve diferenças significativas para acúmulo de massa de matéria seca, massa de carbono e energia/ há. Os clones com melhor desempenho foram aqueles que se desenvolveram em Turmalina; com relação a esses mesmos parâmetros, o clone 1 sobressaiu em relação aos demais, na localidade de Turmalina; em termos de acúmulo de massa seca, o clone 2 apresentou o pior desempenho em Turmalina; em Itacambira, o melhor desempenho em acúmulo de massa de matéria seca, massa de carbono e energia foi observado no clone 2 .

Os clones 1 e 3 apresentam melhor desenvolvimento em Turmalina. Em Itacambira, os melhores resultados foram para o clone 2 .

Recomenda-se o plantio do clone 1 na localidade de Turmalina e do clone 2 em Itacambira, para a produção de energia pela combustão direta ou conversão em carvão vegetal.

\section{AGRADECIMENTOS}

À Fundação de Amparo à Pesquisa de Minas Gerais (Fapemig), ao Conselho Nacional de Desenvolvimento Científico e Tecnológico (CNPq) e ao Grupo Temático de Carvão Vegetal “G6”, pelo apoio.

\section{REFERÊNCIAS}

ASSOCIAÇÃO BRASILEIRA DE PRODUTORES DE FLORESTAS PLANTADAS - ABRAF. 2012. Anuário estatístico da ABRAF: ano base 2011. Brasília, 2011. 150p.

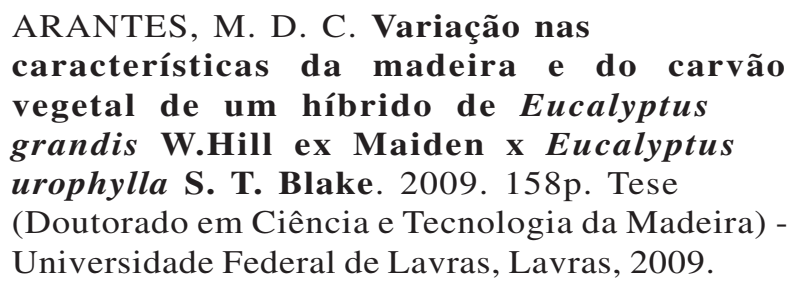

\section{ASSOCIAÇÃO BRASILEIRA DE NORMAS} TÉCNICAS - ABNT. Normas técnicas NBR 11941. Brasília: 2003. 6p.
BRITO, J. O.; TOMAZELLO FILHO, M.; SALGADO, A. L. B. Produção e caracterização do carvão vegetal de espécies e variedades de Bambu. IPEF, n.36, p.13-17, 1987.

CASTRO, A.F.N.M. Efeito da idade e de materiais genéticos de Eucalyptus sp. na madeira e carvão vegetal. 2011.97p. Dissertação (Mestrado) - Universidade Federal de Viçosa, Viçosa, 2011.

FREDERICO, P. G. U. Influência da densidade e composição química da madeira sobre a qualidade do carvão de Eucalyptus grandis W. Hill ex Maiden e de híbridos de Eucalyptus grandis X Eucalyptus urophylla S.T. Blake 2009. 66f. Dissertação (Mestrado em Ciência Florestal) - Universidade Federal de Viçosa, MG, 2009. 66p.

GOMIDE, J. L. et al. Caracterização tecnológica, para produção de celulose, da nova geração de clones de Eucalyptus no Brasil. Revista Árvore, v.29, n.1, p.129-137, 2005.

MAGALHÃES, J. G. R. A energia que vem da floresta. In: Biomassa: energia dos trópicos em Minas Gerais, Belo Horizonte: Universidade Federal de Minas Gerais, 2001. p.133-144.

MONTAGU, K. D.; KEARNEY, D. E.; SMITH, R. G. B. The biology and silviculture of pruning planted eucalypts for clear wood production: a review. Forest Ecology and Management, v.179, n.1, p.1-13, 2003.

OLIVEIRA, A. D.; LIMA, J. T.; ROSADO, S. C. S. Estimativa de massa lenhosa em povoamentos de Eucalyptus spp. Ciência e Prática, v.15, n.4, p.345-348, 1991.

QUIRINO, W. F. et al. Poder Calorífico da madeira e de resíduos lignocelulósicos. Biomassa \& Energia, v.1, n.2, p.173-182, 2004.

RAMOS E PAULA, L. et al. Characterization of residues from plant biomass for use in energy generation. Cerne, v.17, n.2, p.237-246, 2011.

Revista Árvore, Viçosa-MG, v.36, n.5, p.971-980, 2012 
ROCHA, M. F. V. Influência do espaçamento e da idade na produtividade e propriedades da madeira de Eucalyptus grandis x Eucalyptus camaldulensis para energia. 2011. 84f. Dissertação (Mestrado em Ciência Florestal) Universidade Federal de Viçosa, Viçosa, MG, 2011

SANTOS, R. C. et al. Correlações entre os parâmetros de qualidade da madeira e do carvão vegetal de clones de eucalipto.

Scientia Forestalis, Piracicaba, v.39, n.90, p.221-230, 2011.
TRUGILHO, P. F. et al. Estimativa de carbono fixado na madeira de um clone hibrido Eucalyptus urophylla e Eucalyptus grandis. Cerne, v.16, p.33-40, 2010. (Suplemento)

VALE, A. T. et al. Produção de energia do fuste de Eucalyptus grandis HILL EX-MAIDEN e Acacia mangium WILLD em diferentes níveis de adubação. Cerne, v.6, n.1, p.83-88, 2000.

VITAL, B. R. Métodos de determinação de densidade da madeira. Viçosa: SIF, 1984. 21p. (Boletim Técnico, 1). 